\title{
MujeRES EN PANDILLAS SALVADOREÑAS Y LAS PARADOJAS DE UNA AGENCIA PRECARIA
}

\section{Women in Salvadoran Gangs and the paradoxes of a precarious agency}

\author{
María Santacruz Giralt \\ Universidad del País Vasco (España)/Universidad Centroamericana «José Simeón Cañas» (El Salvador)
}

\section{Keywords}

Women gang members

Female transgressors Identity Subjection

ABSTRACT: The phenomenon of maras or gangs in El Salvador has constituted an object of frequent study due to its becoming, over the past twenty years, a brutal manifestation of Salvadoran postwar violence. However, the approaches to the phenomenon tend to grant less centrality to the women who have integrated gangs. Based on feminist theories, in this text I pose the hypothesis that this omission is not only related to their minority situation in these groups, but also to the ways in which the link between women, transgression and violence is usually addressed, by associating passivity or limited agency with femininity in contexts of vulnerability and harm. I propose that the complexity of approaching these figures rests on the tensions and paradoxes that their violent action entails, since their incorporation into a group such as Salvadoran gangs - which seeks homologation in/of identity through the exercise of violence- means that agency can only be produced from their subjection and simultaneous deviation from the (male) frame of production of the gang-member-prototype. Based on bibliographical research and analysis of biographical interviews carried out with women who have been members of gangs, I propose that the agency they can develop is precarious since it is built from the subjection to the group norm. As women, they have to constantly show and reiterate that (male) gang identity, on which not only the laborious construction of a reputation depends, but their survival in hostile, unpredictable and violent environments.

\begin{abstract}
Palabras clave
Pandilleras

Transgresoras

Identidad

Agencia

Sujeción

RESUMEN: El fenómeno de las maras o pandillas en El Salvador se ha constituido en objeto de estudio frecuente al haber devenido, a lo largo de los últimos años, en una brutal manifestación de las violencias salvadoreñas de posguerra. Sin embargo, las aproximaciones al fenómeno suelen conceder menos centralidad a las mujeres que las han integrado. En este texto avanzo, a partir de teorias feministas, sobre la hipótesis de que esta omisión no solo se relaciona con su situación minoritaria en esos grupos, sino con las formas en que suele abordarse el vínculo entre mujeres, transgresión y violencia, al asociar pasividad o agencia limitada con feminidad en contextos de vulnerabilidad y daño. Propongo que la complejidad del abordaje de estas figuras descansa en las tensiones y paradojas que conlleva su acción violenta, puesto que su incorporación a un grupo como las pandillas salvadoreñas - que busca la homologación en/de la identidad a través del ejercicio de la violencia- supone que la agencia solo puede producirse a través de su sujeción y simultánea desviación del marco (masculino) de producción del pandillero-prototipo. A partir de investigación bibliográfica y del análisis de entrevistas biográficas realizadas con mujeres que han sido miembros de pandillas, propongo que la agencia que éstas pueden desarrollar es precaria al construirse a partir de la sujeción a la norma del grupo. En tanto mujeres, han de mostrar y reiterar constantemente esa identidad pandillera (masculina) de la que dependerá no solo la construcción laboriosa de una reputación, sino su superviviencia en entornos hostiles, imprevisibles y violentos.
\end{abstract}

Correspondencia a / Correspondence to: María Santacruz Giralt. Universidad Centroamericana José Simeón Cañas. Departamento de Sociología y Ciencias Políticas. Módulo A de Profesores. Boulevard Los Próceres, Antiguo Cuscatlán, La Libertad, El Salvador. - msantacruz@uca.edu.sv - http://orcid.org/0000-0001-8943-0776.

Cómo citar / How to cite: Santacruz Giralt, María (2019). "Mujeres en pandillas salvadoreñas y las paradojas de una agencia precaria»; Papeles del CEIC, vol. 2019/1, papel 206, 1-20. (http://dx.doi.org/10.1387/pceic.19552).

Recibido: marzo, 2018; aceptado: octubre, 2018.

ISSN 1695-6494 / ㄷ 2019 UPV/EHU 
Cuando se habla de o escribe sobre El Salvador se piensa en violencia, específicamente, la protagonizada por colectivos mediáticamente muy visibilizados como las pandillas callejeras (Cruz, Rosen, Amaya y Vorobyeva, 2017; Dudley y Silva, 2018; International Crisis Group [IcG], 2017; Sala Negra de El Faro, 2013). Y cuando se piensa, habla o escribe sobre éstas, la representación inicial es la de colectivos formados por hombres jóvenes violentos. Si bien esto es cierto, hay una parcela de este complejo fenómeno que suele constituirse en objeto fuera de foco: las mujeres que también las habitan y conforman.

El objetivo general de este artículo es problematizar algunas formas que puede tomar la agencia de mujeres que habitan espacios dominados por hombres violentos - una mara 0 pandilla-, en uno de los países más violentos del mundo: El Salvador. Concretamente, plantea la complejidad en el abordaje de las tensiones de la «agencia de la vulnerable» en el caso de mujeres a las que, tanto por pertenecer a una pandilla como por la representación dominante de feminidad vinculada a la pasividad (Gilfus, 2006), se les podría presumir a priori carentes de agencia. Se parte de la hipótesis general de que las diversas situaciones de violencia experimentadas por estas mujeres en su biografía han contribuido en forma decisiva a la construcción de una identidad que busca su expresión y objetivación en la pandilla. No obstante, paradójicamente, su incorporación a grupos como las pandillas, que buscan una homologación en/de la identidad a través del ejercicio de la violencia, supondrá que ésta podrá producirse únicamente en la medida que la mujer se apropie, a la vez que se desvie, del marco productor de un «pandillero-prototipo». Esto es, sus posibilidades de agencia vendrán dadas a través de su sujeción a la normativa del colectivo. Pero ese movimiento de sujeción a la norma produce regímenes de acción que, a su vez, marcan distancias y estrategias distintas respecto de las utilizadas desde el modelo masculino.

Para poder transitar por este argumento, el artículo comienza brindando un repaso del contexto en el que las pandillas encontraron, tras el fin de la guerra civil salvadoreña (1992), un campo fértil para su expansión. Tras ello, se plantean algunos elementos teóricos para pensar la transgresión femenina, específicamente, la de mujeres en pandillas desde las posibilidades de emancipación o de sujeción que ofrece el espacio. En un tercer momento se analizan algunas de las paradojas que parecieran dar forma a la agencia de estas mujeres, entre otras, su sujeción a la pandilla como condición de posibilidad para la agencia, o la reinvención de la propia posición de vulnerabilidad mediante la incorporación a un espacio tan posibilitador como violento y amenazante. El artículo cierra con unas breves reflexiones sobre la problematización de la agencia en estas mujeres, puesto que ésta se produce en el entrecruce entre la sujeción a y el distanciamiento estratégico respecto de la normatividad de la pandilla.

Este texto está basado en dos investigaciones. Por un lado, un trabajo de investigación documental (revisión de literatura sobre la transgresión femenina y de diversos estudios empíricos sobre el fenómeno de las pandillas y las mujeres que las habitan) realizada como parte del trabajo de campo de mi tesis doctoral, en la que analizo las formas en que se construye y gestiona la identidad entre mujeres que pertenecen o pertenecieron a pandillas o maras

\footnotetext{
1 Agradezco a María Martínez su confianza, paciencia y valiosas observaciones; así como a Iván Orellana y las/os revisoras/es anónimas/os de Papeles del CEIC por sus comentarios a versiones previas de este artículo.

2 Término con el que se le conoce y denomina a una pandilla en la región centroamericana.
} 
en El Salvador. Y, por otro lado, en un proyecto de investigación que coordiné, denominado "Estudio sobre mujeres en pandillas» ${ }^{3}$, cuyo objetivo principal era aproximarse al estudio de mujeres incorporadas a alguna de las dos pandillas más grandes en el país (Mara Salvatrucha y Barrio 18). Las reflexiones de este artículo se sustentan en dos técnicas de producción de información: la investigación documental (apartados de reconstrucción histórica y análisis teórico del objeto de estudio) y las entrevistas biográficas.

De estas últimas se desprende que las mujeres entrevistadas contaban con edades que oscilaban entre los 23 y 39 años en el momento de realizar la entrevista; la mitad de ellas no había superado los estudios básicos y la otra mitad, había iniciado o culminado sus estudios de bachillerato. La mayoria (14) tenía hijos/as, y se incorporaron a una edad muy temprana a su pandilla (promedio de 13,7 años): nueve de ellas lo hicieron con 13 años o menos; el resto, entre los 14 y 16 años. Dada su temprana incorporación, sus trayectorias en la pandilla superaban la década en prácticamente todos los casos.

\section{2.

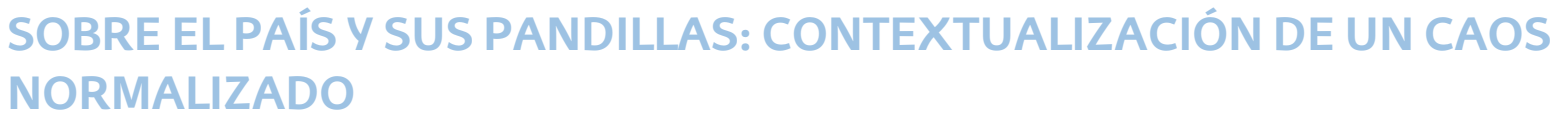

El Salvador es un país cuya historia ha pivotado alrededor de distintas violencias que han jugado un papel configurador de la subjetividad de su población y de su dinámica social antes, durante y posterior a la guerra civil (1980-1992); por lo que narrar la ubicuidad de la violencia y la muerte en la cotidianidad salvadoreña es tarea complicada 4 . Pasa por mostrar históricamente no solo su normalización, sino la banalización de su excesividad; por plantear que es la violencia la que ordena y normaliza un caos que excede la "compulsión contabilizadora» (Orellana, 2015: 166) del registro/ análisis de las elevadas cifras de homicidios, extorsiones o desapariciones - aunque esto cae en el campo de lo inconmensurable-. Pasa por señalar que no se trata solo de una elevada producción de muerte (12 personas asesinadas a diario, en promedio (FUNDAUNGo, 2016)), sino de «las formas en que ésta se produce ${ }^{5}$ " (Blair, 2005: 7). Producción de violencia y muerte que no terminó con la guerra civil, pues a más de veinticinco años de firmados los Acuerdos de paz, su elevada cifra prevalece hasta ahora: ubicado geográficamente en una de las regiones más violentas en el mundo, El Salvador ocupa uno de los primeros lugares en el ranking de países violentos a nivel mundial (Mc Evoy y Hideg, 2017; United Nations Office on Drugs and Crime [UNODC], 2014).

3 Esta investigación fue financiada por Cordaid de Holanda (Memisa-Mensen in Nood-Vastenaktie) y realizada desde el Instituto Universitario de Opinión Pública (ludop) de la Universidad Centroamericana "José Simeón Cañas», en El Salvador (Santacruz y Ranum, 2010). Se llevaron a cabo entrevistas y grupos focales con mujeres en pandillas, y entrevistas a profesionales y funcionarios que trabajan en ese campo. De las entrevistas, 16 fueron realizadas a mujeres que cumplian una sentencia en prisiones salvadoreñas, parte de cuyo análisis se presenta en este artículo. El espacio en que se ejecutaron las entrevistas fue una condición de posibilidad ineludible para la realización de dicho trabajo de campo; y al no ser éste - la prisión-el eje del analítico del artículo su problematización será dejada de lado por razones de espacio.

4 La bibliografía sobre la(s) violencia(s) en El Salvador es amplísima, imposible citar sin hacer injustas y desacertadas omisiones; y hacer un recorrido por ella conduciría a un excurso que trasciende el argumento del artículo.

5 Informes locales muestran la militarización de la seguridad pública, patrones sistemáticos de desapariciones, ejecuciones extrajudiciales, ensañamiento en las muertes, mutilaciones en los cuerpos, entre otros (ludop, 2014; Tutela Legal del Arzobispado, 2007; Valencia, Martínez y Valencia, 2015). 
A inicios de la década de los noventa, las pandillas empezaron a ser visibles como actores en la geografía caótica y transicional de posguerra (Argueta, Caminos, Mancía y Salgado, 1991; Cruz y Portillo, 1998; Cruz, 2010; Levenson, 1988; Sala Negra de El Faro, 2013; Santacruz y Cruz, 2001; Savenije, 2009; Smutt y Miranda, 1998). Dos pandillas surgidas en California, Estados Unidos - la Mara Salvatrucha (MS) y la pandilla de la Calle 18-, se posicionaron en dicho escenario como rivales a muerte ${ }^{6}$, atrayendo a jóvenes de estratos socioeconómicos marginales a sus filas. Sus propiedades se vieron modificadas y fortalecidas, inicialmente, por masivas migraciones y deportaciones entre El Salvador y Estados Unidos durante la década de los noventa, de donde las pandillas importaron modelos y prácticas culturales y de identidad (Cruz, 2007, 2010; Marroquín, 2007; Martel, 2006; Martínez y Sanz, 2013, 2012; Smutt y Miranda, 1998; Valenzuela, 2007a, 2007b).

Durante la última década del siglo $x x$ y lo que va del $x x I$, las maras se han constituido en frecuente objeto de estudio, a nivel local ${ }^{7}$ e internacional (Bruneau, Dammert y Skinner, 2011; Cruz et al., 2017; Dudley y Silva, 2018), pues con el paso de los años han devenido en una singular y brutal manifestación de las violencias salvadoreñas. Su constitución en redes criminales "con rasgos de organizaciones transnacionales» (Cruz, 2010: 379), su progresiva clandestinización y la intensificación en sus niveles de organización se explican atendiendo a las condiciones de posibilidad que el contexto salvadoreño facilitó (políticas de represión de línea dura, ausencia del Estado en los territorios, violencias generalizadas) para que agrupaciones dispersas y callejeras de jóvenes en los noventa devinieran, entre el cierre de un siglo y el inicio de otro, en unas de las pandillas más brutales y estructuradas del hemisferio occidental (ibid.). Conforme las pandillas se transformaron, los objetos y temas de investigación sobre éstas hicieron lo propio, constituyendo un campo bastante denso a nivel local. Aun así, las aproximaciones locales al fenómeno de las pandillas suelen conceder menos centralidad a las mujeres que las integran. Una omisión que no es exclusiva de la región centroamericana, sino que se remonta a las formas en que se ha abordado el vínculo entre mujeres y transgresión (o la violencia).

\section{SOBRE MUJERES Y AGENCIAS EN EL MUNDO (MASCULINO) DEL CRIMEN: ¿EMANCIPACIÓN O SUJECIÓN?}

La dificultad teórica para abordar la agencia de las mujeres en su vertiente transgresora/ criminal puede rastrearse hacia finales del XIX, cuando la Criminología se establece como disciplina para el estudio de la desviación de la norma penal, pero con una mirada centrada en el hombre-fuera-de-la-ley (the Outlaw Man) (Chesney-Lind, 1986; Chesney-Lind y Pasko, 2013). La transgresión/criminalidad de las mujeres no formaba parte de la discusión o investigación

6 En sus inicios, la MS y la 18 eran colectivos con un ideario de horizontalidad expresado en sus vínculos y retórica, que compartían fuertes marcas de identidad y pertenencia, integradas mayoritariamente por hombres jóvenes, organizadas en células adscritas a territorios específicos (barrios, calles, espacios públicos) cuya «defensa» frente a la pandilla rival era la base de su dinámica. Estas características han variado profundamente (Cruz, 2010; Cruz et al., 2017; ludop, 2014; Sala Negra de El Faro, 2013).

7 Como el de la violencia, el campo de las pandillas es también muy nutrido; ver: Carranza (2005); Cruz (2010, 2007); Dudley y Silva (2018); Eric, Ideso, Idies y ludop (2001, 2004a); Eric, Idies, ludop, Nitlapán y Dirinpro (2004b); $\operatorname{lcg}(2017)$. 
criminológica. Más bien, se la entendía desde una metáfora médico-religiosa —síntoma de enfermedad moral (Lombroso, 1893/2004) -; como producto de desajustes personales o psiquiátricos (Juliano, 2010, 2009); y sus modalidades estaban definidas según género (Juliano, 2010): la prostitución era la desviación entendida como "propia» de las mujeres. Y si la transgresión se abordaba, lo era de forma patologizada, trivializada y altamente (hetero) sexualizada (Bunn, 2012; Chesney-Lind y Pasko, 2013; Downing, 2009; Foucault, 1976/2009; Garot, 2008; Sjöberg y Gentry, 2007). Así, aquellas que se desviaban de la norma penal ocupaban un puesto importante en las "taxonomías de la monstruosidad" (Lombroso, 1893/2004), que delimitarían las expectativas de género de la primera mitad del siglo xx.

Aún con la introducción de nuevas perspectivas como consecuencia de la segunda ola del feminismo (Gamble, 2001; Kemp y Squires, 1997) y de la emergencia de una criminología feminista, el abordaje de la transgresión femenina ha estado marcado por estereotipos que subrayan la ausente/limitada/pasiva agencia que se presupone característica femenina, o por un conocimiento construido a propósito de la transgresión masculina (Chesney-Lind, 2006; Smart en Swart, 1991). Así, para aproximarnos a la figura que nos interesa - la mujer en la pandilla-, hay que tener en cuenta este marco de omisiones y miradas estereotipadas sobre la transgresión femenina, en un campo tradicionalmente masculino: el mundo de "lo criminal» (de su ejercicio, de su gestión, de su estudio, de sus opiniones expertas). Será desde este gran marco - que cuando se enfoca en la agencia de la transgresora (si la toma en cuenta) se centra en "vulnerabilidades" de diverso tipo- que se deriva la observación de la mujer que habita estos mundos a través de su pertenencia a una pandilla.

\section{CHICAS Y MUJERES EN LA PANDILLA: ¿EMANCIPACIÓN O SUJECIÓN?}

Aun entre la vasta y longeva producción de la academia estadounidense sobre las pandillas ${ }^{8}$, las experiencias de las mujeres han sido abordadas, hasta recientemente, con menos énfasis en comparación con el conocimiento producido sobre los hombres (Campbell, 1984; Chesney-Lind y Hagedorn, 1999; Chesney-Lind y Pasko, 2013; Curry, 1999; Cyr y Decker, 2003; JoeLaidler y Hunt, 2001; Miller, 2001; Moore, 1991, 2007; Sutton, 2017).

La primera alusión directa a la figura de la chica/mujer en la pandilla en coordenadas estadounidenses se hace en el estudio clásico de Thrasher (1927/1999). Si bien fue el primero en aproximarse sociológicamente a esta cuestión, interpretó la participación femenina como subsidiaria de la dinámica del colectivo y su agencia como producto de su «carácter sexualizado y promiscuo». Consideraba que, para ser aceptadas en igualdad de términos en ese ámbito, éstas tenían que «abandonar los rasgos femeninos» y adoptar el "rol de chico/de hombre» (ibídem: 11-22). Interpretaciones apegadas y reproductoras de un modelo hegemónico (y binario) de feminidad que entendía a las mujeres como actrices secundarias $u$ objetos sexuales del colectivo. Las miradas que se sucedieron sobre esta figura se enfocaron, de hecho, en la necesidad de vigilar a la agente: su legibilidad pasaba por centrarse en la indecencia/desviación de sus acciones, frente a

8 Referencia obligada para el estudio de las experiencias de las mujeres en estos colectivos, por concentrar una de las tradiciones más longevas en la investigación sobre pandillas (Hagedorn, 2008; Klein y Maxson, 2006; Thrasher, 1927/1999). Aunque a veces enfatizan categorías o análisis no siempre extrapolables al contexto salvadoreño/centroamericano, proveen claves teóricas importantes para el análisis. 
lo cual, una forma de "mantenerlas en línea» era a través del "fomento de su feminidad» (Chesney-Lind y Hagedorn, 1999: 2). La interpretación de la transgresión femenina -encarnada ahora en el cuerpo de las pandilleras - se centró, también, en aspectos endógenos: desajustes personales, su «ineptitud social, falta de atractivo físico o impedimentos psicológicos» (Molidor, 1996: 52), en la estética no normativa de sus cuerpos, en la amoralidad e indecencia de sus conductas (Chesney-Lind, 1993; Downing, 2009; Mendoza-Denton, 2008; Sjöberg y Gentry, 2007). Asimismo, su incorporación a la pandilla era entendida como pasajera en su trayectoria biográfica, hasta que la maternidad/el casamiento precipitaran su salida. Estas perspectivas sobre el papel periférico o sexualizado de la agencia de las mujeres en pandillas se mantuvieron por muchas décadas (Curry, 1999; Cyr y Decker, 2003; Molidor, 1996; Moore, 2007).

A medida que el involucramiento de mujeres en pandillas y en sus dinámicas de violencia extrema se hizo más notorio (Chesney-Lind y Pasko, 2013; Fishman, 1999; Lanctôt y Le Blanc, 2002; Miller, 2001; Miller y Decker, 2001; Moore, 2007), los enfoques sobre estas mujeres comenzaron a variar. No fue hasta la década de los ochenta del siglo xx que los enfoques sobre la mujer en la pandilla experimentaron un giro (Molidor, 1996), al situar también su atención en el contexto de vulnerabilidades experimentadas por las mujeres en estos espacios ${ }^{9}$. La participación de las mujeres en pandillas pasó a interpretarse, progresivamente, no solo a partir de factores endógenos o por su posición de cuidadoras/asistentes/satélites de la pandilla, sino a vincularse con la utilidad y posibilidades que la pandilla podía ofrecer (Quicker, 1974/1999) para que la mujer se desarrollara como "un miembro más» en ella (Fishman, 1999; Miller, 2001). Esto es, se comenzaron a vislumbrar las posibilidades que la pandilla ofrecía para el ejercicio de (cierta) agencia a través de su participación en la violencia.

En un grosero intento de simplificación, podríamos señalar con Miller (2001) la existencia de dos grandes líneas teórico-interpretativas sobre las experiencias de las mujeres en la pandiIla. En un extremo de ese "espectro epistemológico" se situarian posturas (ilustradas a partir de Campbell $(1984,1987,1999)$ que interpretarían la participación de la mujer en la pandilla como posibilitadora de oportunidades concretas de liberación/emancipación de las constricciones, mandatos y parámetros de feminidad tradicional en contextos precarizados. Desde estas lógicas, el involucramiento de la mujer en la pandilla le permitiría la consecución de cierta igualdad con respecto a los hombres a la que no sería factible arribar por otros medios, en contextos de múltiples precariedades. A riesgo de sobre simplificar estas miradas, esta narrativa - que enfatiza las posibilidades de agencia- entendería la pandilla como espacio de emancipación/ liberación/posibilidad. Al otro extremo nos encontraríamos con posturas que (ilustradas a partir de Moore $(1991,2007)$ ) plantearian que en la participación femenina en las pandillas destacan las facetas de victimización y vulnerabilidad extremas, no solo por los contextos de marginación de los que provienen, sino por su condición minoritaria en colectivos que ejercen un tipo de masculinidad violenta. Estas posturas enfatizarian que, para las mujeres, las ganancias potenciales de su involucramiento en la pandilla no compensan los riesgos y perjuicios asumidos. Así, esta narrativa se situaría en el otro polo del espectro: la pandilla como espacio de victimización y costos sociales adicionales y de largo plazo para las mujeres. Una postura que destacaría la sujeción, subordinación y, en consecuencia, su nulo o limitado margen de agencia y/o resistencia.

9 Una condición que se cumple, persistente e históricamente, son los contextos social y económicamente marginados y precarizados de los que provienen las chicas y mujeres que integran estos colectivos. 
Sobre este dilema entre sujeción o emancipación, entre posibilidad de agencia o su negación, mi posición es una híbrida: mantener, más que resolver, la tensión entre ambas polaridades. Entender la pandilla como un espacio ambivalente, que otorga posibilidades de agencia al mismo tiempo que impone lógicas de acción particulares y victimización adicional. Una postura que concuerda con la de Miller (2001), quien destaca la necesidad de superar visiones esencialistas sobre las experiencias de las mujeres en la pandilla, entendidas únicamente desde su victimización/vulnerabilidad, o solo desde las posibilidades emancipatorias que podría ofrecer ese espacio. La complejidad del mismo y la heterogeneidad de las experiencias de las agentes conducen a problematizar esa dicotomía. Ni su incorporación a la pandilla debe analizarse como el producto automático y lineal de una historia de victimización; ni sus acciones debiesen ser entendidas como formas de "resistencia activa" a dicha historia. Se trata de mujeres que habitan un espacio complejo, que las expone a riesgos inauditos, simbólicos y literales, que las victimiza/sujeta y también ofrece posibilidades, que las sitúa en posiciones de ambigüedad, paradójicas. Sin embargo, en la medida en que se esfuerzan en la consolidación trabajosa e interminable de "una identidad pandillera», construyen en ese proceso posibilidades - así sean precarias- de agencia.

\section{MUJERES EN (Y DE) LA PANDILLA EN COORDENADAS SALVADOREÑAS}

Al hacer un recorrido por la producción local de los últimos veinte años, la alusión a mujeres en pandillas salvadoreñas/centroamericanas mantiene una tónica marginal frente a los objetos de investigación que han interesado localmente (Argueta et al., 1991; Cruz, 2007; Cruz et al., 2017; Cruz y Portillo, 1998; Demoscopia, 2007; Interpeace, 2011; Levenson, 1988; Santacruz y Concha Eastman, 2001; Santacruz y Ranum, 2010). Aun así, esos estudios señalan características importantes sobre las mujeres en esos espacios: $a$ ) su presencia (minoritaria); $b$ ) las diversas precariedades vitales que les afectan y pueden favorecer, bajo diversas circunstancias, su incorporación a las pandillas; c) unas trayectorias biográficas caracterizadas por el entrecruce de violencias experimentadas antes de su incorporación; $d$ ) la funcionalidad que puede asumir la pandilla frente a contextos precarizados; y e) que ellas también ejercen violencia.

Si pudiera destacarse una tendencia común en esos estudios, diría que es su énfasis en la victimización, el daño y la vulnerabilidad de las mujeres que integran estos colectivos. Sin que se carezca de razón ${ }^{10}$, a fin de trasladar la dificultad de sobrevivir en este tipo de grupos, mucho de la producción local también transmite una representación de la mujer en la pandilla reducida a una de sus dimensiones posibles: la de la mujer avasallada, sujetada, victimizada, sin agencia. Creo que ubicarse solo en un extremo de dicha tensión (el de la vulnerabilidad en su concepción solo como daño) simplifica la complejidad de la cuestión. Coincido con planteamientos que destacan la posición de vulnerabilidad y de múltiples precariedades de las mujeres que habitan las pandillas: su desventaja respecto a un sujeto masculino hegemónico y violento, el machismo y la homofobia propias del espacio, sus necesidades de adaptación y

10 Sobre todo teniendo en cuenta cómo la exclusión, la ausencia del Estado, la debilidad institucional y las diversas vulnerabilidades socioeconómicas de los barrios que habitan y controlan las pandillas se intersectan con las violencias experimentadas por las mujeres que se relacionan con éstas de alguna forma (Sala Negra de EI Faro, 2013). 
supervivencia a través de una serie de acciones precavidas (Gatti, 2007; Santacruz, 2012). En lo que me distancio es en la perspectiva con la que se traslada dicha complejidad: la vulnerabilidad, aunque omnipresente, no debiese descartar o excluir las posibilidades -así fuesen precarias-del ejercicio de algún tipo agencia; al menos, desde los significados que pudieran tener su incorporación, su sujeción a la pandilla o sus prácticas violentas, por ejemplo. Dada la complejidad del asunto, me decanto por una mirada que atienda a cuestiones entendidas como incompatibles: considerar la posibilidad de los perjuicios como de las ganancias, de las pérdidas como de las ventajas que para estas agentes pudiera suponer habitar y sobrevivir la pandilla. La entendería entonces como un tipo de agencia tan precaria (frágil e inacabada, en un constante hacerse, con imposibilidad de resolución absoluta) como paradójica (que aloja posiciones contrapuestas).

\subsection{La precariedad de la agencia: vullnerabilidades de partida}

Yo siempre digo: ¿para qué enamorarse de la vida si, al final, nos casaremos con la muerte? (EMP8 ${ }^{11)}$

El adjetivo precario/a alude a inestabilidad, a algo endeble, a su carácter perecedero. En este caso, pretende traducir la fragilidad - que no transitoriedad- de una posición que pudiera entenderse como propia de quienes se encuentran en el límite del marco de reconocimiento de la vida humana (Butler, 2006) y, por este diferencial de recursos, estar más expuestos a las violencias y la muerte. Adjetivar la agencia de estas mujeres como precaria me permite también trasladar que entiendo su construcción alejada de los modelos modernos desde los que suele leerse su producción: desde un sujeto soberano, unificado y coherente, que actúa de forma autónoma, racional (Dubet, 2010; Gilson, 2016; Weber, 1921/1987). En este caso, ese modelo se rompe. La precariedad de la agencia de estas mujeres $-y$ de ahí, la dificultad de su análisis - radica en la ambigüedad de sus múltiples y simultáneas posiciones, pues de ese constante trabajo dependerá su supervivencia.

\subsubsection{Experiencias tempranas con la violencia y aproximaciones a la pandilla}

Buscaba comprensión, amor, familia... (...) protección. Pero no lo encontré, es una pantalla, no son más ni menos que la familia, uno nace y morirá solo (EMP7).

La pandilla es un espacio que funciona bajo lógicas distintas, no-formalizadas, clandestinas. Aun asi, ofrece la promesa de la solidaridad, la posibilidad de pertenencia a mujeres instaladas en una serie de vulnerabilidades previas a su incorporación: experiencias con la violencia a nivel de sus contextos más cercanos e inmediatos (la familia), y la presencia de agentes de violencia en sus barrios. El espacio del hogar suele plantearse como uno de los primeros escenarios en los que se familiarizan y aprenden a sobrevivir la violencia.

Nunca tuve una relación como de hija-madre, madre-hija, no recuerdo que ella me estuviera abrazando, que dijera que me quería; no me aconsejaba. Lo único que hacía era golpearme, gritarme, maltratarme. (EMP12)

1 Nomenclatura utilizada para identificar a las entrevistadas: EMP (entrevista mujer-en-pandilla), seguida del número correlativo de identificación. Tampoco se utilizó su alias a fin de preservar el anonimato. 
Él [el padrastro] era malo. Le pegaba mucho a mi mamá. Viví mucho eso. Era bolo [ebrio], hasta consumía drogas (...). Él le pegaba a mi mami, yo de niña le decía: «¡No le pegués a mi mamá!», y a mí me decía cosas desagradables. Una vez, cuando le pegó a mi mamá, yo le pegué (...) me fui de la casa, o no me fui... me echaron. Quizás mi mami lo quería demasiado a él... (EMP16)

Ella [su madre] lo ignoraba todo: que me habian violado, que me había acompañado, que tomaba drogas... pero, luego de un rato de estar ahí [en la casa de su madre], la pareja de mi mamá la puso a elegir, y mi mamá me pidió que me fuera porque él era el que la mantenía... (EMP4)

Se alude constantemente a situaciones de abandono, vulnerabilidades socioeconómicas, agresiones físicas entre progenitores $u$ otros miembros de la familia: i.e., la experiencia de un contexto hostil desde los espacios más íntimos. Por ejemplo, el caso de las agresiones sexuales (violaciones) -formas muy reiteradas de violencia en las vidas de estas mujeres según los registros de las entrevistas-, en las que se trataría de experiencias de dominación masculina concretas y encarnadas.

Yo bien vi que se acercaba un hombre (...) y agarró a mi hermanita (...) agarré a la niña para que no le pasara nada, y el hombre me violó a mí, y mi hermana vio todo lo que estaba pasando... Yo no dije a nadie lo que me había pasado, solo le dije a mi abuela que me habían robado el dinero [de la venta]; mi abuela me pegó y me regañó porque me lo habían robado, pero no me hallé en valor de contarle lo que me había pasado. (EMP4)

Yo me sentía mal (...) me sentía lo peor, desgraciada, odiaba a los hombres... y yo siempre decía que me iba a desquitar, pero al final lo mataron [al hombre que la violó]. (EMP5)

A esos espacios inmediatos problemáticos se une la presencia ubicua de diversas violencias en los barrios, encarnadas en los pandilleros como actores centrales. En las entrevistas se destaca un hilo común: figuras masculinas cuya presencia es notoria en las experiencias de riesgo y violencia. No solo previo a su ingreso a la pandilla, por las experiencias de victimización a manos de parientes cercanos o personas extrañas; sino, sobre todo, por la aproximación y posterior incorporación a un colectivo de hombres violentos, a partir de sus vínculos de parentesco o afiliación con figuras masculinas vinculadas al ejercicio de la violencia y el crimen, quienes aparecen reiteradamente en los recuentos de experiencias atravesadas por el ejercicio de la violencia.

Un Palabrero ${ }^{12}$ vendía droga, pero la gente le quería mucho; él te ayudaba. (EMP10)

Cuando él llegó [el encargado de reclutar a jóvenes para la pandilla] (...) nos comenzó a explicar que al unirse, ahí íbamos a tener respeto, así como a él, que nadie lo tocaba. Nos comenzó a dar una gran escuela. (EMP9)

A lo largo de las entrevistas asoma una constante retórica de la carencia: la reiterada alusión al déficit, al abandono, al vacío, la ausencia o la vulnerabilidad (falta de orientación, carencia de protección, ausencia de apoyo, necesidad de pertenencia)... frente a lo cual, la idea sería colmarlas o resolverlas - reinventarse a partir de la violencia- mediante su incorporación a esa maquinaria compleja que es la pandilla. Ya fuera como recurso para protegerse

12 Líder local o encargado de una célula de la pandilla. 
de un barrio peligroso o un hogar problemático, por una temprana andadura en pareja con un pandillero o como la posibilidad de encarnar la promesa de una identidad, muchas se fueron aproximando a la pandilla como producto de un traslape de circunstancias. Frente a las múltiples precariedades y riesgos que supone la vida en barrios controlados por pandillas, y en contraposición a su abandono por parte del Estado, la biografía tiene su peso al valorar la pandilla como forma posible de habitarlos y sobrevivirlos. Pero la vez, su aproximación e incorporación, la búsqueda de una alternativa que posibilita acceso a poder simbólico y concreto ya nos habla de la posibilidad de agencia.

\subsubsection{Mundos de vida en medio de la muerte}

En la mara/pandilla, el mundo es diferente. Todo lo normal se vuelve anormal, y todo lo anormal es normal. Es el mundo al revés. (EMP12)

Incorporarse a la pandilla y adquirir el estatus de pandillera, lejos de entenderlo como la inauguración de "una nueva identidad" o una transformación producto del desplazamiento de una identidad de origen (no-pandillera) a una de llegada (pandillera), lo concibo como una serie de procesos, como un trabajo constante y complejo que trasciende el rito de paso de la incorporación ${ }^{13}$. Más que "convertirse en pandillera» se deviene tal en forma progresiva; para lo cual han de asumir e incorporar una normatividad distinta, establecida y marcada por el ejercicio de una masculinidad violenta: desde la incorporación misma se intenta comprobar, por la vía más física, que la aspirante es tan ruda y resistente, como uno más (Miller, 2001).

Cuatro Homeboys ${ }^{14}$ cholos [corpulentos] me dieron una zapateada de respeto... por xx segundos... Quedé morada de la cara, con sangre en un ojo. (EMP4)

Aguantar una taleguiada [paliza] de xx segundos [para ingresar]. Me golpearon cuatro, igual que a un hombre. (EMP1, énfasis mío)

Es difícil, porque uno ingresa a otro mundo (...). Antes me habían dicho que lo pensara bien, que luego de brincada [incorporada] todo iba a ser una obligación (...) ya una vez dentro, no se puede uno (sic) salir ni hacer lo que uno quiera, y me lo dijeron... (EMP5)

El ingreso a través de una práctica equivalente respecto a los miembros masculinos es solo el primer paso de un trayecto que busca consolidar prestigio y respeto por medio de la demostración - performativa- de que la feminidad que encarnan no es compatible con la normatividad ni la representación generalizada (sobre todo, desde la pandilla) de lo que, en teoría, caracteriza el régimen de acción de "una mujer»: no son débiles ni inseguras (sobre todo, frente a una posición entendida como debilitada por su propia historia de victimización y los contextos precarizados de procedencia). En un espacio en que lo masculino-violento constituye la norma, deben ajustarse a esos parámetros para mostrarse como tales. Para funcionar en ese nuevo mundo, la progresiva construcción de identidad pandillera

13 Brincarse, en el argot de la pandilla. Al momento de realizar el trabajo de campo, consistía en una paliza de duración variable, propinada por otros miembros de la pandilla a la que se aspiraba ingresar, y que marcaba su ingreso formal. Aunque su estabilización y progresiva posición dependerá más bien de la participación posterior de la mujer en la dinámica propia de la pandilla, vinculada con el uso extremo de la violencia (Carranza, 2005; Santacruz y Ranum, 2010).

14 Término para referirse a los pandilleros hombres. 
es clave. Hay que actuar desde ese nuevo régimen basado en el ejercicio de la acción (violenta).

Cuando te brincan [se incorporan], te dan la taca [sobrenombre] y la cancha [territorio/ubicación], y tu tribu/clica [célula]... o sea, qué territorio tenés y por qué te has brincado... pero vos no sos nadie de la noche a la mañana, lo ganás con respeto... (EMP7; énfasis míos)

Por mi carácter y mis acciones [iba ganando respeto]. Siempre hacía lo que había que hacer. Y con el carácter, uno llega donde uno lo permite. Sí, yo me di el respeto, yo me lo gané (...). Me he portado bien en la pandilla. Para lo malo sí he servido; tal vez no para lo bueno, pero para lo malo sí... Uno cosecha lo que uno siembra. En la pandilla, yo tengo mi respeto. (EMP12; énfasis míos)

Quizás [se metió a la pandilla] porque a mí me gustaba inspirar miedo...a mí me gustaba que me tuvieran miedo, así la gente no iba a estar con cosas con uno. (EMP15)

Esa progresiva construcción de identidad pandillera -inaugurada en el rito de ingreso a partir de la asignación de un nuevo nombre (alias), un nuevo territorio (físico y simbólico) y una historia (la de su pandilla o su clika), elementos clave para la configuración de identidad (Gatti, 2007) - se va estabilizando a partir de la ejecución de una serie de acciones violentas propias de la dinámica del colectivo. La construcción de estatus pasa por la producción de una identidad y una reputación acorde con esas nociones de fuerza y dureza, y en la pandilla eso solo se logra mediante el ejercicio directo y extremo de la violencia.

\subsection{Las paradojas de una agencia precaria: el trabajo (inacabable) de devenir pandillera}

A medida que la dinámica violenta y la ubicuidad de la muerte pasan a ser parte de la cotidianidad, la acción acorde es práctica obligada para sobrevivir un espacio que persigue la homogeneidad entre sus integrantes, pero cuyo "miembro prototípico" está muy alejado de sus posiciones. Una de las formas para acercarse a ese modelo (masculino) de identidad pandillera es proyectarse y actuar -en términos de agencia pero, también, performativos (Butler, 1990; 2002) - conforme a las expectativas que el colectivo sostiene sobre la integrante: a partir de la reiteración de sus normas, la repetición de sus reglas, la recreación constante de gestos vinculados con el uso de la violencia como formas de mostrarse y narrarse como un Homeboy más.

Le dejé ir los tres disparos [le disparó tres veces] y salí corriendo... sentí que nunca llegaba al carro (...). Ellos [en la clica] celebraron por mí... yo, yo llorar quería, era raro, todo había pasado tan rápido... un gran nerviosismo (...) pero luego, todo ese nerviosismo, todo eso, se quita con el tiempo. (EMP9)

De repente, pararon el carro y me dijeron: «vas a disparar»... tenía como 12 años (...) agarro el arma, disparo a uno de los contrarios (...) yo no podía disparar, solo le di, y cuando sentí, le había pegado. (EMP4)

En tanto las mujeres tienen puntos de partida distintos a los del modelo que pretenden emular, al reactivar constantemente ese marco de normas, incorporan y reproducen también en sus prácticas una serie de innovaciones, de pequeños gestos diferenciadores respecto al 
"guión de pandillero" (Butler, 2002, 1990). Una de estas es la acción prudente (Gatti, 2007): una agente reflexiva a la vez que condicionada por reglas que, incluso va «conociendo sobre la marcha, en el hacer mismo" (ibídem: 171). Una agente insegura/desconfiada (Santacruz, 2012), como parte de un régimen de acción orientado al ejercicio de la supervivencia. Unas prácticas enmarcadas en un contexto donde nada es estable (precario), basadas en un conocimiento práctico del mundo. En suma, de cara a un contexto que cambia constantemente, a discreción de la pandilla o de actores fuera de ella, sus miembros también han de intentar adaptarse a esa inestabilidad, seguir las reglas, pero con lealtad insegura e hipervigilante.

Es que, mire, esto de la pandilla es algo que hay que saberlo llevar... (EMP5)

Yo les alegaba, les reclamaba porque sentía que no era justo... A veces reaccionaban [los pandilleros] sólo por chambres [chismes] (...), y yo les decía: «Si somos hermanos, ¿para qué nos vamos a estar matando?». Y me daban duro, yo aguantaba por dar mi opinión. (EMP9)

Uno miraba las cosas que había que hacer... y yo, adentro de todo. Una vez (...) pasó un contrario (...) todos se le fueron encima, empezaron a puyarlo [acuchillarlo]. Yo me salí, y me quedé viendo todo (...) quería meterme, decirles que le dejaran en paz (...), pero no me podía meter porque me iban a matar a mí también. (EMP10)

La pandilla es un espacio muy complejo, cambiante, amenazado, amenazante y ambivalente. Cuestión que se evidencia en las variables y contradictorias atribuciones de significado que las agentes le otorgan en forma progresiva al espacio mismo, a medida que su incorporación se materializa y estabiliza: de ser valorada como espacio de posibilidad/oportunidad/supervivencia, pasa a ser experimentada simultáneamente como espacio de coacción/amenaza, incluso contra la vida. La contradicción de un espacio que reúne en sí mismo tanto la expectativa del amparo como la certeza de la persecución y la alta posibilidad de la muerte puede derivar también en cambios en las definiciones de la propia pertenencia.

Yo le pregunté a mi palabrero [líder de su célula]: «Si se supone que esto es una sola familia, ¿por qué nos matamos a nosotros mismos?» Él me dijo: «Es que árbol que no da fruto, hay que cortarlo, ¿para qué se va a tener?» "Ese reglamento no me lo leyeron", le dije yo; "El barrio nunca te va a mostrar una sola cara, acá, te vas a dar cuenta de muchas cosas», me dijo... Y así fue: así como hice, asi vi hacer, y asi me hicieron. (EMP 5)

En su caso, sus acciones han de ajustarse a las reglas, conducirse en forma apropiada, "mostrando constantemente la foto" (EMP4), estando a la altura. Hay "hipervigilancia» de parte de sus compañeros/as, vigilancia que ellas también ejercen sobre otros y sobre ellas mismas, por hábito, por práctica cotidiana, por conveniencia, por supervivencia. Y a medida que pasa el tiempo, su experiencia en la pandilla se torna un constante despliegue de estrategias de diverso tipo: para posicionarse en el grupo, para ganar reputación o urespeto», para sobrevivir. A medida que pasa el tiempo, el compromiso hacia el grupo es mayor, ya no solo por solidaridad o complicidad, sino porque en esa capacidad de adaptación a la dinámica y en la obligación de ajustarse a los condicionamientos del colectivo suele estar la clave para posicionarse mejor, pero también para sobrevivir - ellas y/o su familia - a la pandilla misma, a la contraria pero también a la propia.

Eso me resentía que, en la pandilla, si cometés una marca [un error], con la familia se meten, y eso era mi miedo. (EMP 10) 
Los civiles [personas de la comunidad] me buscaban a mí para que les hiciera paros [favores], que les ayudara... Es que a mi nunca me han gustado las injusticias... vaya, por ejemplo, había una señora bien viejita que vendía cocos, y yo no dejaba que a ella le cobraran renta [extorsión]; o cuando subian los contrarios y le pedian los cocos, se los bebían sin pagarle. Yo los plomeaba [disparaba]. Pero por hacer esas cosas, me pararon el carro en la pandilla, me dijeron que yo iba a caer por un clavo [problema] de un civil, y que si eso pasaba, ellos no me iban a ayudar (...). Ya después, con el tiempo, la gente me cerraba las ventanas... porque me tenían miedo... y bueno, cuando andaban así, entonces yo sí les daba una razón para que me tuvieran miedo... (EMP 9)

Este proceso de construcción de identidad pandillera es una práctica laboriosa, un trabajo constante que deviene en experimentación y eventualmente, en experiencia (Dubet, 2010). Es decir, una agente que se sabe inscrita en un "modelo» desde el que actúa y que habita, pero al cual también ha de adaptarse, y en ese movimiento muestra "la arbitrariedad que constituye su personaje» (Gatti, 2007:184). En este caso, las narrativas de las mujeres en las pandillas sobre su propia biografía muestran, en unos casos con más énfasis que en otros, a agentes que se esfuerzan por encarnar y actuar un modelo de pandillero que van conociendo en el camino. Para ello, asumen una multiplicidad enorme de gestos: una estética, unas prácticas concretas y modos de estar que se constituyen en las normas y expectativas a las que han de ajustarse, pues es la pandilla quien dictamina lo apropiado, lo procedente, lo proscrito, lo obligatorio. En esto, el ejercicio de la violencia es central: deviene acción banal y excesiva. Y también, para algunas, en acción desencantada, ejercida por conveniencia o supervivencia. En un espacio que pivota alrededor de la violencia, la posición de la mujer (y la construcción de su estatus) estará mediada por las posibilidades que tenga de demostrar, de exhibir que se encuentra a la altura de sus expectativas. Conocen las reglas, saben lo que tienen o hay que hacer, la mayoría de veces se cumplen y pocas veces se objetan, pues eso tiene costos.

Se siente emocionante [pertenecer a un grupo en el que la mayoría son hombres], es difícil, pero lo veía como un reto: ellos contra mí... Al principio, me analizaban como mujer, me probaban, y mi reto era «soy mujer, pero valgo igual, si ellos pueden, yo también». (EMP1)

Vamos creciendo porque tal vez uno hace algo y se sabe a nivel de todos... «vos sos fulana de tal clika, he escuchado de vos». Si uno es bueno, se sabe... Lo bueno para nosotros es malo, verdad... (EMP16)

Tenés que ser pensante, salir adelante, demostrar con hechos, hacer cosas, no solo hablar... Por ejemplo, si yo decía "vamos a hacer una pegada [ataque]", yo también tenía que ir, yo me lo jugaba, y con todo. Así, iba ganándome el respeto (...), y me respetaron. (EMP8; cursivas mías)

Haciendo una apretada síntesis, no se trata de satélites pasivos de sus pandillas, sino de agentes que actúan su membresía y desarrollan una serie de tácticas y un constante trabajo que les permite sobrellevar (y sobrevivir) esa pertenencia. Acciones que, por una parte, recogen una progresiva desconfianza hacia lo que les rodea (dentro y fuera de la pandilla), que acumula desencantos y miedos; y que, por otra, les ha permitido la construcción de una posición, una subjetividad y una identidad. Una trayectoria que ha supuesto progresivas obligaciones y ajustes a normativas explícitas, implícitas e incluso paralelas, exclusivas para las mujeres. Que ha implicado la necesidad de encarnar y construir una identidad que, en la 
práctica, nunca estará del todo culminada. No solo porque el teórico "punto de llegada» sea un modelo de contornos masculinos, sino porque el proceso mismo de construcción de esa identidad pandillera supone, simultáneamente, su modificación a partir de un sinnúmero de gestos propios, de paradojas y contradicciones. Su posición como «mujeres-en-las-pandillas» exige el apego a un guión y a determinados regímenes de acción masculinizados. Pero, en tanto mujeres, la expectativa de la pandilla es la observación y cumplimiento de prácticas y nociones que reproducen también lógicas tradicionales y normativas de feminidad: mujeres dispuestas no solo a la violencia, sino al cuido de sus miembros, mujeres obedientes. Es así como esta tensión -irresoluble, a mi juicio- ofrece luces sobre las formas que quizá el asunto pueda ser pensado: que el régimen de acción de la mujer en la pandilla obliga a tener presente que su incorporación, a la vez que las sitúa en nuevos y complejos escenarios de vulnerabilidad, les provee posibilidades de agencia, aunque sea como victimaria.

\section{REFLEXIONES FINALES: LA AGENCIA DESDE LA SUJECIÓN}

El ejercicio de violencia por mujeres en pandillas desestabiliza las narrativas dominantes sobre lo que, supuestamente, caracteriza una feminidad normativa: su vulnerabilidad, su desamparo $y$, sobre todo, su incapacidad de ejercer violencia. Estas mujeres rompen con muchas representaciones dominantes y unidireccionales, que representan "la mujer» como víctima o testigo, pero no como agente de violencias (Åhäll, 2012; Brown, 2014; Chesney-Lind, 1986; Juliano, 2009; Sjöberg y Gentry, 2007). Son cuerpos marcados como femeninos, normalmente asociados con una posición de pasividad, victimización y vulnerabilidad (Gilson, 2016), por tanto, su agencia transgrede las interpretaciones más usuales (y simplistas) sobre lo que "le sucede a la mujer cuando entra en contacto con la violencia»: convertirse en su víctima. Y las problematiza, pues es en la posibilidad y oportunidad mismas de ejercer violencias que estas mujeres desafían esas presunciones (culturales y normativas) de partida. Al tratarse de biografias atravesadas por diversidad de violencias, se les podría incluso entender o representar como víctimas y, con ello, producir un ajuste entre dicha categoría y la entidad ontológica que se le presupone prototípica: «la mujer». Sin embargo, el que éstas hayan devenido, a su vez, en agentes que ejercen violencias las remueve de esa categoria, pues las instala en una posición opuesta a la de víctima: una victimaria, un cuerpo que no (solo) ha sido depositario de violencias, sino que las ha ejercido.

Estas lógicas paradójicas rompen con nociones esencializadas o universalizadas de la mujer (cuerpos que encarnarian la supuesta pasividad y fragilidad de la víctima), sin que abunden interpretaciones alternativas que tomen en cuenta estas contradicciones y que problematicen la forma tradicional de entender la agencia. En este sentido comparto con Gilson (2016: 75) su concepción matizada de vulnerabilidad, quien no la feminiza ni la reduce a mera susceptibilidad o predisposición al daño, o a pasividad frente al mismo, sino como condición compleja, ontológicamente compartida y compatible incluso con la posibilidad de agencia: «la vulnerabilidad [es construida] como una condición que necesariamente conduce al daño, del cual es realmente solo una precondición». Entender la vulnerabilidad desde esa «ambigüedad" (ibídem: 87) - e.g.: una víctima no tiene que carecer de agencia para representarse y entenderse como tal- posibilita una aproximación más compleja y matizada a las experiencias de victimización. 
La dificultad de pensar la agencia desde estos colectivos vulnerabilizados pasa por el intento de problematizar su construcción desde la sujeción: es a partir de su subordinación a la norma de la pandilla (y su implicación con la violencia) que se dan sus posibilidades de agencia, al someterse a la vez que distanciarse (estratégicamente) de ella. Así, cuando la mujer se encuentra más comprometida con la dinámica de su pandilla -cuando está activa, en sus términos-, es cuando despliega una agencia excesiva en la violencia. Y es ahí, en esa ebullición de acción cuando su sujeción a la normatividad de la pandilla ( $y$ al modelo hegemónico de "lo pandillero») es absoluta: "la potencia del sujeto parece ser efecto de su subordinación" (Butler, 2010: 12). Reproduce, actúa sus condiciones de sujeción (el modelo hegemónico de "pandillero-violento»), se implica de lleno en la normativa existente (Gatti, 2007), y eso pasa por su constitución como agente de violencia. Sin embargo, esto se ejecuta desde la vulnerabilidad de su posición dentro del colectivo: las mujeres actúan sobre la base de un modelo, emulando un centro normativo de identidad (pandillera), pero un poder con límites, con fisuras: «quien promete la continuación de la existencia, explota el deseo de la supervivencia. 'Prefiero existir en la subordinación que no existir'», dice Butler (ibídem: 18). En esos entornos hostiles, imprevisibles y violentos (de la pandilla, del país), su agencia deviene táctica, paradójica, desencantada conforme la mujer habita y combate en el colectivo. Se trata de figuras (vulnerables) instaladas en espacios violentamente precarios ( $y$ precariamente violentos) y en una posición ambivalente, incómoda, desde la que se sigue ejecutando el trabajo de la identidad y la pertenencia (a la pandilla) que es, en muchos casos, el único recurso. La precariedad de la agencia de estas mujeres se deriva de la dificultad de sus múltiples posiciones, de la imposibilidad de conciliación de sus tensiones y del constante trabajo que supone la supervivencia en contextos que no ofrecen garantías, porque lo que ofrecen para sobrevivir, para reinventarse, para obtener reconocimiento, para ser agente, es la posibilidad y el ejercicio de la violencia y la experiencia de la muerte.

\section{REFERENCIAS}

Åhäll, L. (2012). Motherhood, Myth and Gendered Agency in Political Violence. International Feminist Journal of Politics, 14(1), 103-20.

Argueta, S., Caminos, G., Mancía, M. y Salgado, M. (1991). Diagnóstico sobre los grupos Ilamados "maras» en San Salvador. Factores psicosociales que prevalecen en los jóvenes que los integran. San Salvador: Universidad Centroamericana «José Simeón Cañas».

Blair, E. (2005). Muertes violentas. La teatralización del exceso. Medellín: Universidad de Antioquia.

Brown, S. (2014). Female Perpetrators of the Rwandan Genocide. International Feminist Journal of Politics, 16(3), 448-69.

Bruneau, T.; Dammert, L. y Skinner, E. (Eds.). (2011). Maras. Gang Violence and Security in Central America. Austin: University of Texas Press.

Bunn, G. (2012). The Truth Machine: A Social History of the Lie Detector. Baltimore: Johns Hopkins University Press. 
Butler, J. (1990). Performative Acts and Gender Constitution: An Essay in Phenomenology and Feminist Theory. En S.E. Case (Ed.). Performing Feminisms: Feminist Critical Theory and Theatre. (pp.270-82). Baltimore \& London: Johns Hopkins University Press.

Butler, J. (2002). Cuerpos que importan: sobre los límites materiales y discursivos del "sexo". Buenos Aires: Paidós.

Butler, J. (2006). Vida precaria. El poder del duelo y la violencia. Buenos Aires: Paidós.

Butler, J. (2010). Mecanismos psíquicos del poder. Teorías sobre la sujeción. 2a ed. Madrid: Cátedra.

Campbell, A. (1984). The Girls in the Gang. New York: Basil Blackwell.

Campbell, A. (1987). Self-Definition by Rejection: The Case of Gang Girls. Social Problems, 34, 451-66.

Campbell, A. (1999). Female Gang Members' Social Representations of Aggression. En M. Chesney-Lind y J. Hagedorn (Eds.). Female Gangs in America: Essays on Girls, Gangs and Gender (pp. 248-55). Chicago: Lakeview Press.

Carranza, M. (2005). Detención o muerte: hacia dónde van los «pandilleros» de El Salvador. En L. Dowdney (Ed.). Ni guerra, ni paz: comparaciones internacionales de niños y niñas en violencia armada organizada (pp. 242-266). Río de Janeiro: COAV, Viva Río, ISER e IANSA.

Chesney-Lind, M. (1986). Women and Crime: The Female Offender. Signs: Journal of Women in Culture and Society, 12(1), 78-96.

Chesney-Lind, M. (1993). Girls, gangs and violence: anatomy of a backlash. Humanity and Society, 17, 321-44.

Chesney-Lind, M. (2006). Patriarchy, Crime and Justice. Feminist Criminology in an Era of Backlash. Feminist Criminology, 1, 1, 6-26.

Chesney-Lind, M. y Hagedorn, J. (1999). (Eds.). Female Gangs in America: Essays on Girls, Gangs and Gender. Chicago: Lakeview Press.

Chesney-Lind, M. y Pasko, L. (2013). The Female Offender: Girls, Women and Crime. $3^{\text {rd }}$. Ed. Thousand Oaks: Sage.

Cruz, J.M. (2007). (Ed.) Street Gangs in Central America. San Salvador: UcA Editores.

Cruz, J.M. (2010). Central American maras: from youth street gangs to transnational protection rackets. Global Crime, 11(4), 379-398.

Cruz, J.M. y Portillo, N. (1998). Solidaridad y violencia en las pandillas en el Gran Salvador. Más allá de la vida loca. San Salvador: UCA Editores.

Cruz, J.M. y Carranza, M. (2006). Pandillas y políticas públicas: el caso de El Salvador. En J. Moro (Ed.). Juventudes, violencia y exclusión. Desafios para las políticas públicas. Guatemala: Magna Terra Editores.

Cruz, J. M., Rosen, J. D., Amaya, L. E., y Vorobyeva, Y. (2017). La nueva cara de las pandillas callejeras: El fenómeno de las pandillas en El Salvador. Recuperado de https://lacc.fiu.edu/ research/la-nueva-cara-de-las-pandillas_reporte-final_esp.pdf 
Curry, G. (1999). Responding to Female Gang Involvement. En M. Chesney-Lind y J. Hagedorn (Eds.). Female Gangs in America: Essays on Girls, Gangs and Gender (pp. 133-53). Chicago: Lakeview Press.

Cyr, J. y Decker, S. (2003). Girls, Guys and Gangs: Convergence or Divergence in the Gendered Construction of Gangs and Groups. Journal of Criminal Justice, 31, 423-33.

Demoscopia. (2007). Maras y pandillas, comunidad y policía en Centroamérica. Guatemala: autor.

Downing, L. (2009). Murder in the Feminine: Marie Lafarge and the Sexualization of the Nineteenth-Century Criminal Woman. Journal of the History of Sexuality, 18, 1, 121-37.

Dubet, F. (2010). Sociología de la experiencia. Madrid: Editorial Complutense y Centro de Investigaciones Sociológicas.

Dudley, S. y Silva, H. (2018). La MS-13 en América. Cómo la pandilla callejera más notoria del mundo escapa a toda lógica y se resiste a ser destruida. Washington, D.C.: InSight Crime $\&$ Center for Latin American \& Latino Studies.

ERIC, IDESO, IDIES y IUDOP (2004a). Maras y pandillas en Centroamérica. Pandillas y capital social. Volumen II. San Salvador: UCA Editores.

ERIC, IDIES, IUdOP, NitLAPÁn y DiRINPRo (2004b). Maras y pandillas en Centroamérica. Políticas juveniles y rehabilitación. Volumen III. Managua: UcA Publicaciones.

ERIC, IDESO, IDIES y IUDOP (2001). Maras y pandillas en Centroamérica. Volumen I. Managua: UCA Publicaciones.

Fishman, L. (1999). Black Female Gang Behavior. An Historical and Ethnographic Perspective. En M. Chesney-Lind y J. Hagedorn (Eds.). Female Gangs in America: Essays on Girls, Gangs and Gender (pp. 64-84). Chicago: Lakeview Press.

Foucault, M. (2009). Historia de la sexualidad I. La voluntad de saber. Buenos Aires: Siglo XXI Editores.

Fundación Guillermo Manuel Ungo. (Fundaungo). (2016). Evolución de los homicidios en El Salvador, 2009-junio de 2016. Boletín 04: Aportes al debate sobre la seguridad ciudadana. Recuperado de: http://www.fundaungo.org.sv/pdf/2016/28112016_ Aportes_4homicidios.pdf

Gamble, S. (2001). (Ed.). The Routledge Companion to Feminism and Postfeminism. London \& New York: Routledge/Taylor \& Francis Group.

Gatti, G. (2007). Identidades débiles. Una propuesta teórica aplicada al estudio de la identidad en el País Vasco. Madrid: Centro de Investigaciones Sociológicas.

Garot, R. (2008). Norma Mendoza-Denton's Homegirls: Language and Cultural Practice among Latina Youth Gangs. Crime, Media, Culture, 4, 285-89.

Hagedorn, J. (2008). Armed Young Men and Gangsta Culture. Minneapolis: University of Minnesota.

Instituto Universitario de Opinión Pública. (IUDOP). (2014). La situación de la seguridad y la justicia 2009-2014. Entre expectativas de cambio, mano dura militar y treguas pandilleras. San Salvador: autor. 
Interpeace Regional Office for Latin America, Poljuve e Instituto de Estudios Comparados en Ciencias Penales de Guatemala (ICCPG) (s.f.). Violentas y violentadas. Relaciones de género en las maras Salvatrucha y Barrio 18 del triángulo norte de Centroamérica. Guatemala: autores.

International Crisis Group (ICG). (2017). El salario del miedo: maras, violencia y extorsión en Centroamérica. Informe sobre América Latina $n .^{\circ}$ 62. Recuperado de https:// www. crisisgroup.org/es/latin-america-caribbean/central-america/62-mafia-poor-gangviolence-and-extortion-central-america

Joe-Laidler, K. y Hunt, G. (2001). Accomplishing Feminity among Girls in the Gang. British Journal of Criminology, 41, 656-678.

Juliano, D. (2009). Delito y pecado. La transgresión en femenino. Política y Sociedad, 46(1/2), 79-95.

Juliano, D. (2010). Excluidas y marginales. Una aproximación antropológica. Madrid: Cátedra.

Kemp, S. y Squires, J. (1997). (Eds.). Feminisms. Oxford \& New York: Oxford University Press.

Klein, M. y Maxson, C. (2006). Street Gangs. Patterns and Policies. New York: Oxford University Press.

Lanctôt, N. y Le Blanc, M. (2002). Explaining Deviance by Adolescent Females. Crime G Justice, 29, 113-202.

Levenson, D. (1988). On Their Own: A Preliminary Study of Youth Gangs in Guatemala City. Guatemala: Cuadernos de investigación Avancso.

Lombroso, C. y Ferrero, G. (1894/2004). Criminal Woman, the Prostitute and the Normal Woman. Durham, N.C.: Duke University Press.

Marroquín, A. (2007). Indiferencias y espantos. Relatos de los jóvenes de pandillas en la prensa escrita de Centroamérica. En G. Rey (Coord.). Los relatos periodisticos del crimen (pp. 55-91). Bogotá: Centro de Competencia en Comunicación. Fundación Friedrich Ebert.

Martel, R. (2006). Las maras salvadoreñas: nuevas formas de espanto y control social. Estudios Centroamericanos, 696, 957-979.

Martínez, C. y Sanz, J. (2012). El viaje de la Mara Salvatrucha. Capitulo I. El origen del odio. Recuperado de http://www.salanegra.elfaro.net/es/201208/cronicas/9301/

Martínez, C. y Sanz, J. (2013). El Barrio roto. En Sala Negra de El Faro. Crónicas Negras desde una región que no cuenta. (pp.28-86). Ciudad de México: Aguilar.

Mc Evoy, C. y Hideg, C. (2017). Global Violent Deaths 2017. Time to decide. Recuperado de: www.smallarmssurvey.org/fileadmin/docs/U-Reports/SAS-Report-GVD2017.pdf

Mendoza-Denton, N. (2008). Homegirls. Language and Cultural Practice among Latina Youth Gangs. Massachusetts, Oxford \& Victoria: Blackwell Publishing.

Miller, J. (2001). One of the Guys. Girls, Gangs, and Gender. New York: Oxford University Press.

Miller, J. y Decker, S. (2001). Young Women and Gang Violence: Gender, Street Offending, and Violent Victimization in Gangs. Justice Quarterly, 18, 1, 115-40. 
Molidor, C. (1996). Female Gang Members: A Profile of Aggression and Victimization. Social Work, 41, 3, 251-57.

Moore, J. (1991). Going Down to the Barrio: Homeboys and Homegirls in Change. Philadelphia: Temple University Press.

Moore, J. (2007). Female Gangs: Gender and Globalization. En J. Hagedorn (Ed.). Gangs in the Global City. Alternatives to Traditional Criminology. (pp. 189-224). Chicago: University of Illinois Press.

Oficina de la Naciones Unidas contra la Droga y el Delito (UNODC) (2014). Global Study on Homicide 2013. Trends, Contexts, Data. Recuperado de http://www.unodc.org/gsh/

Orellana, C.I. (2015). Pensar la violencia a contracorriente (Editorial). Estudios Centro americanos, 741,70, 163-69.

Sala Negra de El Faro. (2013). Crónicas Negras desde una región que no cuenta. Ciudad de México: Aguilar.

Santacruz, M. (2012). Forasteras, autómatas y traicioneras. Una adaptación de la teoría sobre las modalidades débiles de la identidad a pandilleras salvadoreñas. Trabajo de fin de máster, inédito. Leioa: Universidad del País Vasco.

Santacruz, M. y Cruz, J. M. (2001). Las maras en El Salvador. En ERIC, IDESO, IDIES y IUDOP. (Vol. I). Maras y pandillas en Centroamérica. Volumen I. (pp.17-107). Managua: UcA Publicaciones.

Santacruz, M. y Concha-Eastman, A. (2001). Barrio adentro. La solidaridad violenta de las pandillas. San Salvador: IUDOP-UCA.

Santacruz, M. y Ranum, E. (2010). «Segundos en el aire»: mujeres pandilleras y sus prisiones. San Salvador: IUDOP-UCA.

Savenije, W. (2009). Maras y barras. Pandillas y violencia juvenil en los barrios marginales de Centroamérica. San Salvador: FlACso-Programa El Salvador.

Smutt, M. y Miranda, J. (1998). El fenómeno de las pandillas en El Salvador. San Salvador: FLACSO-UNICEF.

Sutton, T. (2017). The lives of female gang members: A review of the literature. Aggression and Violent Behavior, 37, 142-152.

Swart, W. (1991). Female Gang Delinquency: A Search for «Acceptably Deviant Behavior». Mid-American Review of Sociology, Xv, 1, 43-52.

Thrasher, F. (1927/1999). Sex in the Gang. En M. Chesney-Lind y J. Hagedorn (Eds.) Female Gangs in America: Essays on Girls, Gangs and Gender (pp. 10-26). Chicago: Lakeview Press.

Valenzuela, J.M. (2007a). Introducción. Cien años de choledad. En Valenzuela, J.M., Nateras, A. y Reguillo, R. (Coords.). Las maras. Identidades juveniles al limite. (pp. 11-32). Ciudad de México: Universidad Autónoma Metropolitana, El Colegio de la Frontera Norte, Casa Juan Pablos. 
Valenzuela, J.M. (2007b). La mara es mi familia. En J.M. Valenzuela, A. Nateras y R. Reguillo. (Coords.). Las maras. Identidades juveniles al límite (pp. 33-62). Ciudad de México: Universidad Autónoma Metropolitana, El Colegio de la Frontera Norte, Casa Juan Pablos.

Valencia, R., Martínez, O. y Valencia, D. (2015). La policía masacró en la finca San Blas. Recuperado de http://www.salanegra.elfaro.net/es/201507/cronicas/17205/La-Policíamasacró-en-la-finca-San-Blas.htm

Weber, M. (1921/1987). Economía y sociedad. Esbozo de sociología comprensiva. 9. ${ }^{\text {a }}$ reimpr. Ciudad de México: FCE. 